\title{
Using the workload indicators of staffing need method to determine the staffing requirements for primary healthcare service delivery in Nigeria
}

\author{
Sunny C. Okoroafor ${ }^{1}$ (D), Agbonkhese I. Oaiya ${ }^{1}$ (1) \\ 1 IntraHealth International, Abuja, Nigeria \\ Keywords: universal health coverage, health workers, Workload Indicators of Staffing Need, Nigeria \\ https://doi.org/10.29392/001c.28359
}

\section{Journal of Global Health Reports}

Vol. 5, 2021

\begin{abstract}
Background
Weak health governance mechanisms and inequitable distribution of health investments exist in Nigeria, and this is negatively affecting the health system, and health workforce availability and performance. This is evident at the primary level of care and necessitates the need to ensure that staffing levels are informed by workloads.
\end{abstract}

\section{Methods}

This study applied the workload indicators of staffing need (WISN) method to determine the staffing requirements for nurses, midwives, community health officers (CHO), community health extension workers (CHEWS), and junior community health extension workers (JCHEWS). It was conducted in 11 purposefully selected primary-level health facilities in two local government areas in Cross River State, Nigeria.

\begin{abstract}
Results
Eighteen health service activities were identified for the primary level of care across the life course. Whilst nurses, midwives, $\mathrm{CHO}$ and CHEWS perform all the activities, the JCHEWS performed 10 of these functions. The staffing requirement findings for the facilities in Calabar Municipal indicated that there were staffing shortages for nurses and midwives in 4 of the 5 sampled facilities, three facilities had sufficient or excess numbers of CHO/CHEWS, and 4 facilities had sufficient or excess numbers of JCHEWS. In Calabar South local government area, the calculated requirement showed a cumulative shortage of 5 nurses/midwives and $26 \mathrm{CHO} / \mathrm{CHEW}$, and appropriate staffing of JCHEWS in 4 facilities.
\end{abstract}

\section{Conclusions}

The results of this study illustrate the staffing needs of nurses, midwives, CHO, CHEWS and JCHEWS in the sampled facilities and indicate the need for using evidence for staffing decisions. This is pertinent considering it ultimately contribute to improvements in service delivery and health indices. The evidence from the application of the WISN tool and the scale-up of its application has the potential of contributing to the achievement of national goals as well as universal health coverage and sustainable development goals.

As countries strive toward achieving national goals, universal health coverage (UHC), and sustainable development goals (SDG), the need to increase the availability and equitable distribution of qualified, skilled, and motivated health workers has become imperative. This is premised on evidence that the functionality of the health system, often synonymous with public level facilities delivering quality health care ${ }^{1}$ is dependent on the availability and equitable distribution of health workers. ${ }^{2}$

Africa faces numerous health workforce challenges that are contributing to the health indices and systems of countries in the continent. They include weak health governance mechanisms and the resultant weak capacity to develop and implement human resources for health (HRH) plans, coordinate partners and optimize the available health workers. The impact of this is enormous as evidence suggests a strong association between effective health system governance and optimized health workforce performance leading to improved health outcomes. ${ }^{1}$ In addition to the weak health governance, are the low stock of health workers, inequitable distribution of existing ones with high densities reported in urban areas and tertiary and secondary levels of care, disparities in production and population needs, high internal and external migration rates, high workloads, poor 
work environment and conditions of service, and poor investment in education. ${ }^{3-6}$

Weak health governance mechanisms and inequitable distribution of health investments exist in Nigeria and this is negatively affecting the health system and health workforce performance. ${ }^{7-9}$ Health workers are facing poor remuneration, high workloads, poor working environments, inadequate medical supplies and equipment, and delayed payment of salaries and emoluments. ${ }^{7,10-12}$ The weak health governance mechanism compounded by inadequate numbers of health workers at the primary level of care, the entry point into Nigeria's health system, necessitates the need to ensure that staffing levels are informed by workloads. This study utilized the Workload Indicator for Staffing Needs (WISN) method ${ }^{8}$ to determine the staffing needs in selected facilities in Cross Rivers State of Nigeria. The results provide the evidence needed to inform policy on posting health workers at the primary level of care which is reported as non-existent. ${ }^{8}$

WISN results provide the evidence needed for achieving equitable distribution of available health workers. WISN, developed by the World Health Organization (WHO), considers the contextual variations in health-seeking behavior, service utilization rates, the daily activities conducted by health workers and the time expended in service delivery, as well as the regional variations in morbidities, in determining staffing needs for effective and efficient service delivery. This methodology was piloted at the same time as this study in Nigeria ${ }^{4}$ based on learnings from other countries. ${ }^{13-17}$

The WISN method is a methodical approach that deepens health care managers' understanding of services, their delivery, inherent complexities, as well as perspectives of health workers on quantity and quality of work and its effect on service providers and clients. The tool helps health care managers determine the numbers of health care workers required for the workload of a facility, and the workload pressure using existing health facility data. ${ }^{18}$ It is useful for staffing decision-making at every level of the health system; simple, acceptable to health service managers; easy for non-medical health managers to understand; and provides realistic practical targets for budgeting and resource allocation. The process involves eight steps: determining priority health workers and type of health facility; estimating available working time; defining workload components; setting activity standards; establishing standard workloads; calculating allowance factors; using WISN to determine staff requirement, and analyzing and interpreting WISN results. ${ }^{18}$ There is sufficient evidence to show that the WISN method is globally accepted and used in several countries to guide health workforce policy development, planning and management. ${ }^{13-17}$

\section{METHODS}

\section{STUDY SETTING}

This study was conducted in government-owned primarylevel health facilities located in Calabar Municipal and Calabar South local government areas of Cross River State. The study was conducted from June 2016 to February 2017 and funded by the United States Agency for International Devel- opment (USAID) under the Nigeria CapacityPlus Associate Award project, led by IntraHealth International.

\section{STUDY DESIGN}

This study applied the WISN method to determine the staffing requirements for frontline health workers that provide promotive, preventive, and curative services for uncomplicated minor ailments at the primary level facilities. These are nurses/midwives and community health practitioners - community health officers (CHO), community health extension workers (CHEW), and junior community health extension workers (JCHEW).

The WISN study was conducted in purposefully selected primary-level health facilities that have been functional at least a year before the commencement of the study. Overall, 11 facilities were included in the study.

\section{DATA COLLECTION}

A data collection tool was developed following a desk review on the data needed to conduct a WISN study based on information available in the WISN software.

The public sector is governed by national and state civil service rules. Information on the working hours per day, working days per week, and authorized and unauthorized absences for the study prioritized cadres were obtained after a desk review of statutory public service rules and other grey literature. Information obtained from the desk review was triangulated during the field data collection process amongst purposefully selected key informants in 11 primary-level facilities.

Data on the current staffing of facilities were obtained from staff registers (nominal rolls) and triangulated with staffing records domiciled centrally in the primary healthcare authority department in the sampled local government areas. Annual health service delivery statistics were sourced from the National District Health Information System (DHIS) 2.0 and facility registers. Information obtained from both sources was also triangulated.

Workload components and the activity standards for the prioritized cadres were identified by an expert group comprising of health workers who were currently employed in the public sector in primary-level facilities. The group was also cadre-specific for nurses/midwives and community health practitioners. Focus group discussions were held with these groups to identify and validate the health service, support, and additional activities and the activity standards.

\section{DATA ANALYSIS AND INTERPRETATION}

The collected data were entered into the WISN software for analysis. Interpretation of the results on staffing levels was done based on the guide in the WISN manual. ${ }^{18}$

\section{ETHICS DECLARATIONS}

Written consent was obtained prior to data collection though the National Code of Research Ethics exempts ethical approval for studies involving the collection of existing data whose sources are publicly available. 
Table 1. Health service activities and service standards for primary level of care

\begin{tabular}{|c|c|c|c|c|}
\hline \multirow[b]{2}{*}{ HEALTH SERVICES } & \multicolumn{3}{|c|}{ SERVICE STANDARDS FOR CADRES } & \multirow[t]{2}{*}{ UNIT TIME } \\
\hline & $\begin{array}{l}\text { NURSES/ } \\
\text { MIDWIVES }\end{array}$ & $\begin{array}{l}\mathrm{CHO} / \\
\text { CHEW }\end{array}$ & JCHEW & \\
\hline Antenatal Clinic (ANC)- First Visit & 50 & 40 & 30 & Minutes / patient \\
\hline $\begin{array}{l}\text { Antenatal Clinic (ANC)- Subsequent Visits/ } \\
\text { Revisits }\end{array}$ & 21 & 25 & 27 & Minutes / patient \\
\hline Routine Immunization & 27 & 23 & 20 & Minutes / patient \\
\hline Child Welfare Clinic (Sick Child) U5 & 35 & 40 & 42 & Minutes / patient \\
\hline Family Planning - Counselled & 15 & 40 & 43 & Minutes / patient \\
\hline Family Planning - Oral & 5 & 5 & 5 & Minutes / patient \\
\hline Family Planning - Injectable & 8 & 10 & 12 & Minutes / patient \\
\hline Family Planning - Insertion & 15 & 16 & & Minutes / patient \\
\hline $\begin{array}{l}\text { Treatment of Minor Ailments (Children and } \\
\text { Adults) }\end{array}$ & 27 & 62 & 61 & Minutes / patient \\
\hline Delivery(Normal Delivery) & 75 & 140 & & Minutes / patient \\
\hline Delivery(Assisted) & 90 & 160 & & Minutes / patient \\
\hline Post Natal Care(Booked Case and Unbooked) & 16 & 25 & & Minutes / patient \\
\hline PMTCT - Mothers (Booked and Unbooked) & 14 & 26 & & Minutes / patient \\
\hline PMTCT - Infant (Booked and Unbooked) & 23 & 28 & & Minutes / patient \\
\hline Accidents \& Emergencies - Minor Cases & 20 & 38 & 29 & Minutes / patient \\
\hline Accidents \& Emergencies - Major Cases & 9 & 10 & & Minutes / patient \\
\hline Care of A Patient With Tuberculosis (TB) & 23 & 33 & & Minutes / patient \\
\hline 2-Way Referrals & 35 & 38 & 35 & Minutes / patient \\
\hline
\end{tabular}

CHO- Community Health Officers; CHEW- Community Health Extension Workers; JCHEW - Junior Community Health Extension Workers

\section{RESULTS}

\section{WORKLOAD COMPONENTS AND ACTIVITY STANDARDS}

There are three kinds of workload components; health service, support, and additional activities. ${ }^{18}$ The health service activities are performed by members of a cadre, and statistics are readily available; support activities are performed by all members of a cadre but statistics are not kept, and additional activities are performed by some members of a staff cadre, and statistics were not available. ${ }^{18}$

The workload components and activity standards developed and validated by the expert group is presented in table $\underline{1}, \underline{2}$, and $\underline{3}$. Eighteen health service activities presented were identified for primary level facilities across the life course. Whilst nurses/ midwives perform all the activities, the JCHEWS performs 10 of these functions under their approved scope of practice. Eleven support and additional activities each, and the corresponding category and individual allowance standards were also identified.

\section{WISN RESULTS}

The WISN results in tables $\underline{4}$ and $\underline{5}$ indicate varying degrees of health workforce shortages and inequitable distribution across the sample facilities in the two local government areas.
For the facilities in Calabar Municipal, there are staffing shortages for nurses and midwives in 4 of the 5 sampled facilities (table 4). For the CHO/CHEW, 3 facilities (Akim PHC, Ediba PHC, and Ikot Ansa PHC) had sufficient or excess stock for their workloads. The staffing levels for the JCHEWS were deficient in 1 facility (Big Qua PHC). Three facilities (Akim PHC, Ediba PHC, and Ikot Ansa PHC) had sufficient or excess staffing for CHO/CHEWs and JCHEWS, with Big Qua PHC, only having sufficient numbers of nurses/ midwives and $92 \%$ of required $\mathrm{CHO} / \mathrm{CHEW}$, and Ikot Omin Polyclinic having an excess of JCHEWS and $67 \%$ of required CHO/CHEWS.

In Calabar South LGA, the WISN calculated requirement showed a cumulative shortage of 5 nurses/midwives and 26 CHO/CHEW. Ekpo Abasi PHC has the highest staff shortage of CHO/CHEWS (14); followed by Essierebom PHC (staff shortage of 7) and the workload pressure for CHO/CHEWs in both facilities are the same. There was $\mathrm{CHO} / \mathrm{CHEW}$ surplus in Anantigha PHC and Anderson PHC. There was appropriate staffing of JCHEWS in 4 PHCs (Anderson PHC, Ekpo Abasi, Essierebom, and Henshaw town) and surplus in 2 PHCs (Akani Esuk HC and Anantigha PHC).

\section{DISCUSSION}

Our study employed the WISN method to determine the 
Table 2. Support activities and category allowance standards for primary level facilities

\begin{tabular}{|c|c|c|c|}
\hline \multirow[b]{2}{*}{ WORKLOAD COMPONENTS } & \multicolumn{3}{|c|}{ ACTUAL WORKING TIME PER CADRE } \\
\hline & $\begin{array}{l}\text { NURSE/ } \\
\text { MIDWIVES }\end{array}$ & $\mathrm{CHO} / \mathrm{CHEW}$ & JCHEW \\
\hline Community Mobilization and Education & 3 hours/ month & 4 hours/month & 8 hours/month \\
\hline Group Health Education & 1 hour/week & 1 hour/week & 1 hour/week \\
\hline Community Development Committees (CDC) meetings & 2 hours/month & 2 hours/month & 2 hours/month \\
\hline Ward Development Committees (WDC) meetings & 3 hours/month & 3 hours/month & 3 hours/month \\
\hline Daily cleaning & 10 minutes / day & 10 minutes / day & 10 minutes/ day \\
\hline Outreaches/Community-based services & 4 hours/month & 20 hours/month & 21 hours/month \\
\hline $\begin{array}{l}\text { Handing over/taking over, Report writing and ward round } \\
\text { (inpatient and outpatient) }\end{array}$ & 90 minutes/day & 90 minutes/day & 90 minutes/day \\
\hline Follow-up care/ Home visits & 3 hours/week & 3 hours/week & 3 hours/week \\
\hline Staff Meetings & 2 hours/month & 2 hours/month & 2 hours/month \\
\hline Documentation on patients & 1 hour/month & 1 hour/month & 1 hour/month \\
\hline Male circumcision & $\begin{array}{l}20 \text { hours/ } \\
\text { month }\end{array}$ & 20 hours/month & \\
\hline
\end{tabular}

CHO- Community Health Officers; CHEW- Community Health Extension Workers; JCHEW - Junior Community Health Extension Workers

Table 3. Additional activities and individual allowance standards for primary level facilities

\begin{tabular}{|c|c|c|c|c|}
\hline \multirow[b]{2}{*}{ WORKLOAD COMPONENTS } & \multicolumn{2}{|l|}{ NURSE/MIDWIVES } & \multicolumn{2}{|l|}{$\mathrm{CHO} / \mathrm{CHEW}$} \\
\hline & $\begin{array}{l}\text { NUMBER OF STAFF } \\
\text { PERFORMING THE } \\
\text { TASK }\end{array}$ & $\begin{array}{l}\text { ACTUAL } \\
\text { WORKING } \\
\text { TIME }\end{array}$ & $\begin{array}{l}\text { NUMBER OF STAFF } \\
\text { PERFORMING THE } \\
\text { TASK }\end{array}$ & $\begin{array}{l}\text { ACTUAL } \\
\text { WORKING } \\
\text { TIME }\end{array}$ \\
\hline Supervision of students & All unit heads & 32 hours/month & All unit heads & 2 hours/week \\
\hline General administration & 1 & 6 hours /month & 1 & $\begin{array}{l}4 \text { hours / } \\
\text { month }\end{array}$ \\
\hline Monthly Report writing & 1 & 1 hour/month & 1 & 1 hour/month \\
\hline $\begin{array}{l}\text { Monitoring and Evaluations/ } \\
\text { Documentations/Collation of } \\
\text { patient data }\end{array}$ & 1 & 3 hours/month & 1 & 3 hours/month \\
\hline $\begin{array}{l}\text { Review meetings (LGA } \\
\text { coordination meeting) }\end{array}$ & 1 & 3 hours/month & 1 & 3 hours/month \\
\hline Mentoring of subordinates & 1 & 4 hours/month & 1 & 4 hours/month \\
\hline LGA Technical Meetings & 1 & 2 hours/month & 1 & 2 hours/month \\
\hline $\begin{array}{l}\text { Management committee } \\
\text { meeting/ Facility Management } \\
\text { Meeting }\end{array}$ & 1 & 2 hours/month & 1 & 2 hours/month \\
\hline Advocacy & 1 & 6 hours/year & 1 & 10 hours /year \\
\hline Bed Making & 2 & 24 minutes /day & 2 & 24 minutes /day \\
\hline Sterilization of equipment's & 1 & 30 minutes/day & 1 & 30 minutes/day \\
\hline
\end{tabular}

CHO- Community Health Officers; CHEW- Community Health Extension Workers; JCHEW - Junior Community Health Extension Workers; LGA - Local Government Area

staffing needs in purposefully selected facilities in Cross Rivers State of Nigeria. Our results indicate shortage and inequity in the health workforce in primary-level facilities. It adds to the existing evidence that highlights the need for policy reforms to match the staffing of health facilities to workloads. ${ }^{4,13-21}$

Our results show varying degrees of shortages and sur- plus. One benefit of the workload methodology is the evidence it generates that is helpful in the redistribution of health staff from locations with less workload to areas with a high workload. ${ }^{17}$ However, staff deployment or redeployment is best recommended for health workers with similar skill-set. The surplus JCHEWs can be redeployed to provide services within their scope of practice with priority given to 
Table 4. WISN results for Calabar Municipal Local Government Area

\begin{tabular}{|c|c|c|c|c|c|}
\hline $\begin{array}{l}\text { NAME OF PRIMARY } \\
\text { HEALTHCARE CENTRE }\end{array}$ & CADRES & $\begin{array}{l}\text { CURRENT } \\
\text { STAFF }\end{array}$ & $\begin{array}{l}\text { REQUIRED } \\
\text { STAFF }\end{array}$ & $\begin{array}{l}\text { WISN } \\
\text { SHORTAGE/ } \\
\text { EXCESS }\end{array}$ & $\begin{array}{l}\text { WISN } \\
\text { RATIO }\end{array}$ \\
\hline \multirow{3}{*}{ Akim HC } & Nurses/midwives & 0 & 1 & -1 & 0.00 \\
\hline & $\mathrm{CHO} / \mathrm{CHEW}$ & 11 & 8 & 3 & 1.38 \\
\hline & JCHEW & 1 & 1 & 0 & 1.00 \\
\hline \multirow{3}{*}{ Big Qua PHC } & Nurses/midwives & 1 & 1 & 0 & 1.00 \\
\hline & $\mathrm{CHO} / \mathrm{CHEW}$ & 12 & 13 & -1 & 0.92 \\
\hline & JCHEW & 0 & 1 & -1 & 0.00 \\
\hline \multirow{3}{*}{ Ediba PHC } & Nurses/midwives & 0 & 1 & -1 & 0.00 \\
\hline & $\mathrm{CHO} / \mathrm{CHEW}$ & 8 & 8 & 0 & 1.00 \\
\hline & JCHEW & 1 & 1 & 0 & 1.00 \\
\hline \multirow{3}{*}{ Ikot Ansa PHC } & Nurses/midwives & 0 & 1 & -1 & 0.00 \\
\hline & $\mathrm{CHO} / \mathrm{CHEW}$ & 15 & 15 & 0 & 1.00 \\
\hline & JCHEW & 4 & 2 & 2 & 2.00 \\
\hline \multirow{3}{*}{ Ikot Omin Polyclinic PHC } & Nurses/midwives & 0 & 1 & -1 & 0.00 \\
\hline & $\mathrm{CHO} / \mathrm{CHEW}$ & 8 & 12 & -4 & 0.67 \\
\hline & JCHEW & 2 & 1 & 1 & 2.00 \\
\hline
\end{tabular}

CHO- Community Health Officers; CHEW- Community Health Extension Workers; JCHEW - Junior Community Health Extension Workers; HC - Health Centre; PHC - Primary Healthcare Centre

Table 5. WISN Results for Calabar South Local Government Area

\begin{tabular}{|c|c|c|c|c|c|}
\hline $\begin{array}{l}\text { NAME OF PRIMARY } \\
\text { HEALTHCARE CENTRE }\end{array}$ & CADRES & $\begin{array}{l}\text { CURRENT } \\
\text { STAFF }\end{array}$ & $\begin{array}{l}\text { REQUIRED } \\
\text { STAFF }\end{array}$ & $\begin{array}{l}\text { WISN } \\
\text { SHORTAGE/ } \\
\text { EXCESS }\end{array}$ & $\begin{array}{l}\text { WISN } \\
\text { RATIO }\end{array}$ \\
\hline \multirow{3}{*}{ Akani Esuk HC } & Nurses/midwives & 0 & 1 & -1 & 0.00 \\
\hline & $\mathrm{CHO} / \mathrm{CHEW}$ & 9 & 11 & -2 & 0.82 \\
\hline & JCHEW & 2 & 1 & 1 & 2.00 \\
\hline \multirow{3}{*}{ Anantigha PHC } & Nurses/midwives & 0 & 1 & -1 & 0.00 \\
\hline & $\mathrm{CHO} / \mathrm{CHEW}$ & 9 & 7 & 2 & 1.29 \\
\hline & JCHEW & 2 & 1 & 1 & 2.00 \\
\hline \multirow{3}{*}{ Anderson PHC } & Nurses/midwives & 0 & 1 & -1 & 0.00 \\
\hline & $\mathrm{CHO} / \mathrm{CHEW}$ & 7 & 6 & 1 & 1.17 \\
\hline & JCHEW & 1 & 1 & 0 & 1.00 \\
\hline \multirow{3}{*}{ Ekpo Abasi PHC } & Nurses/midwives & 1 & 1 & 0 & 1.00 \\
\hline & $\mathrm{CHO} / \mathrm{CHEW}$ & 12 & 26 & -14 & 0.46 \\
\hline & JCHEW & 1 & 1 & 0 & 1.00 \\
\hline \multirow{3}{*}{ Essierebom PHC } & Nurses/midwives & 0 & 1 & -1 & 0.00 \\
\hline & $\mathrm{CHO} / \mathrm{CHEW}$ & 6 & 13 & -7 & 0.46 \\
\hline & JCHEW & 1 & 1 & 0 & 1.00 \\
\hline \multirow{3}{*}{ Henshaw Town PHC } & Nurses/midwives & 0 & 1 & -1 & 0.00 \\
\hline & $\mathrm{CHO} / \mathrm{CHEW}$ & 8 & 11 & -3 & 0.73 \\
\hline & JCHEW & 1 & 1 & 0 & 1.00 \\
\hline
\end{tabular}

ensuring supportive supervision is in place.

Information from this study on the scope of health, support, and additional activities, as well as the time these ac- tivities take to be performed, brings to bear the numerous responsibilities of health workers in this level of care, similar to other findings in Nigeria. ${ }^{4,5}$ It shows that beyond the 
core health service workloads, health workers are also saddled with additional functions that are also very essential in maintaining essential health service provision. Some of these would not be there if relevant trained cadres of health workers are available. These additional workloads are contributing to reported high workloads in the primary level of care and are considered by health workers when they plan to take up or stay in rural postings. ${ }^{10,11,22-24}$ Government should therefore put measures in place to ensure that there is an appropriate skill-mix of health workers to perform these functions.

As the government strives to achieve UHC through primary health care revitalization, the WISN method offers an approach to determining essential health services based on service utilization and the skill-mix of health workers needed for apposite service delivery. Applying this method at a national scale will elicit information that will stimulate investments in the health workforce. It will also provide evidence for the implementation of the task shifting and sharing in contexts where they are most needed as a means of optimizing the use of the existing health workforce. ${ }^{18}$

There were some limitations in our study. The absence of an objectively proven way of obtaining information on the activity standards for the prioritized cadres in the study resulted in varying activity standards obtained during focus group discussions with the expert group. To address this, we ensured that they reached a consensus that was used for the calculations. Also, due to the prolonged non-availability of some cadres and the taking up of these functions by other cadres, we noticed that there was an overlap in functions for some cadres. This was still taken into consideration in the study as this had been the trend over time. The implication of this in the estimations is that the required numbers for some cadres may have been over or under-estimated. Lastly, triangulation of information on the workloads was difficult mainly due to poor documentation in the health facilities. To address this, we opted to use the information available in the national instance of the DHIS as approved by the government.

\section{CONCLUSIONS}

Evidence-based health workforce planning is necessary for ensuring optimal HRH performance in the face of limited fiscal space for HRH planning and management, an embargo on recruitment of health workers, issues of health workforce productivity and performance, and ever-changing health-seeking behaviors of the populace. The results of this study illustrate the staffing needs of nurses, midwives, CHO, CHEWS and JCHEWS in the sampled facilities and indicate the need for using evidence for staffing decisions. This is pertinent considering it can ultimately contribute to improvements in service delivery and health indices. WISN is a proven methodology that focuses on estimating the number of health workers needed and the skill mix required to meet the changing demand for health care. The evidence from the application of this tool and the scale-up of its application has the potential of contributing to the achievement of national goals as well as UHC and the SDGs.

\section{ACKNOWLEDGMENTS}

The authors acknowledge the support of the United States Agency for International Development (USAID) who funded the Strengthening HIV/AIDS Service delivery through Human Resources for Health (HRH) Systems in Nigeria project and this study. Our profound appreciation and immense thanks go to the senior management and staff of the Cross Rivers State Ministry of Health.

\section{ETHICS DECLARATION}

Written consent was obtained prior to data collection though the National Code of Research Ethics exempts ethical approval for studies involving the collection of existing data whose sources are publicly available.

\section{FUNDING}

This work was funded by the United States Agency for International Development (USAID) (Associate Cooperative Agreement \# AID-620-LA-15-00002).

\section{AUTHORSHIP CONTRIBUTIONS}

Conceptualization: SO; Data collection: SO, AO; Analysis: SO; Writing of original draft: SO, AO; Review and editing: SO, AO.

\section{COMPETING INTERESTS}

The authors completed the Unified Competing Interest form at http://www.icmje.org/disclosure-of-interest/ (available upon request from the corresponding author) and declare no conflicts of interest.

\section{CORRESPONDENCE TO:}

\section{Dr. Sunny Okoroafor IntraHealth International 30 Sudan Street, Abuja, Nigeria. sunnyokoroafor@yahoo.com.}

Submitted: August 29, 2021 GMT, Accepted: September 11, 2021 GMT 


\section{REFERENCES}

1. Everybody's Business: Strengthening Health Systems to Improve Health Outcomes: WHO's Framework for Action. World Health Organization; 2007.

2. World Health Organization (WHO). The World Health Report 2006-Working Together for Health. World Health Organization; 2006.

3. Esu EB, Chibuzor M, Aquaisua E, et al. Interventions for improving attraction and retention of health workers in rural and underserved areas: A systematic review of systematic reviews. Journal of Public Health. 2021;43(Supplement_1):i54-i66. doi:1 0.1093/pubmed/fdaa235

4. Okoroafor S, Ngobua S, Titus M, Opubo I. Applying the workload indicators of staffing needs method in determining frontline health workforce staffing for primary level facilities in Rivers state Nigeria. Glob Health Res Policy. 2019;4:35. doi:10.1186/s41256-01 9-0125-Z

5. Okoroafor SC, Ongom M, Mohammed B, et al. Estimating frontline health workforce for primary healthcare service delivery in Bauchi State, Nigeria. Journal of Public Health.

2021;43(Supplement_1):i4-i11. doi:10.1093/pubmed/f daa272

6. World Health Organization (WHO). Road map for scaling up the human resources for health for improved health service delivery in the African Region 2012-2025: Adopted by the Sixty-second session of the Regional Committee. Published online 2013.

7. Federal Ministry of Health. Second National Strategic Health Development Plan (2018-2022).; 2018.

8. Abimbola S, Olanipekun T, Schaaf M, Negin J, Jan S, Martiniuk ALC. Where there is no policy: governing the posting and transfer of primary health care workers in Nigeria. Int J Health Plann Mgmt. 2017;32(4):492-508. doi:10.1002/hpm.2356

9. Adeloye D, David RA, Olaogun AA, et al. Health workforce and governance: The crisis in Nigeria. Hum Resour Health. 2017;15(1):1-8. doi:10.1186/s12960-01 7-0205-4

10. Okoroafor SC, Ongom M, Mohammed B, et al. Perspectives of policymakers and health care managers on the retention of health workers in rural and remote settings in Nigeria. Journal of Public Health. 2021;43(Supplement_1):i12-i19. doi:10.1093/ pubmed/fdaa262
11. Okoroafor SC, Ongom M, Salihu D, et al. Retention and motivation of health workers in remote and rural areas in Cross River State, Nigeria: a discrete choice experiment. Journal of Public Health. 2021;43(Supplement_1):i46-i53. doi:10.1093/pubme d/fdaa236

12. Federal Ministry of Health. National Human Resources for Health Strategic Plan 2021-2025. Federal Ministry of Health; 2020.

13. Govule P, Mugisha JF, Katongole SP, Maniple E, Nanyingi M, Onzima R. Application of workload indicators of staffing needs (WISN) in determining health workers' requirements for Mityana general hospital, Uganda. International Journal of Public Health Research. 2015;3(5):254-263.

14. Kayani NS, Khalid SN, Kanwal S. A study to assess the workload of lady health workers in Khanpur UC, Pakistan by applying WHO's WISN method. Athens $J$ Health. 2016;3(1):65-80. doi:10.30958/ajh.3-1-4

15. McQuide PA, Kolehmainen-Aitken RL, Forster N. Applying the workload indicators of staffing need (WISN) method in Namibia: Challenges and implications for human resources for health policy. Hum Resour Health. 2013;11(1):1-11. doi:10.1186/147 $\underline{8-4491-11-64}$

16. Mugisha JF, Namaganda G. Using the Workload Indicator of Staffing Needs (WISN) methodology to assess work pressure among the nursing staff of Lacor Hospital. Published online 2008.

17. World Health Organization (WHO). Workload Indicators of Staffing Need (WISN): selected country implementation experiences. Published online 2016.

18. World Health Organization (WHO). WISN: Workload Indicators of Staffing Need. User's Manual. World Health Organization; 2010.

19. Burmen B, Owuor N, Mitei P. An assessment of staffing needs at a HIV clinic in a Western Kenya using the WHO workload indicators of staffing need WISN, 2011. Hum Resour Health. 2017;15(1):1-8. doi:1 $\underline{0.1186 / \mathrm{s} 12960-017-0186-3}$

20. Hagopian A, Mohanty MK, Das A, House PJ. Applying WHO's “workforce indicators of staffing need" (WISN) method to calculate the health worker requirements for India's maternal and child health service guarantees in Orissa State. Health Policy and Planning. 2012;27(1):11-18. doi:10.1093/heapol/czr00 $\underline{7}$ 
21. World Health Organization (WHO). Applying the WISN method in practice: case studies from Indonesia, Mozambique and Uganda. Published online 2010.

22. World Health Organization (WHO). Retention of the health workforce in rural and remote areas: a systematic review: web annex A: GRADE evidence profiles. Published online 2020.
23. Robyn PJ, Shroff Z, Zang OR, et al. Addressing health workforce distribution concerns: a discrete choice experiment to develop rural retention strategies in Cameroon. Int J Health Policy Manag. 2015;4(3):169-180. doi:10.15171/ijhpm.2015.27

24. World Health Organization (WHO). Increasing Access to Health Workers in Remote and Rural Areas through Improved Retention.; 2010. 